Tema: Produtos metálicos ferrosos

\title{
DESENVOLVIMENTO DE UM AÇO ULTRA-BAIXO CARBONO EM PROCESSO DE TREFILAÇÃO*
}

\author{
Bruno Mendes Grillo ${ }^{1}$ \\ Luciano Moreira Pessanha² \\ Rodrigo Gonçalves Amorim ${ }^{3}$
}

\section{Resumo}

O presente trabalho tem por objetivo comparar dois aços produzidos em uma aciaria LD em processo de trefilação de arames, sendo um aço ultra-baixo carbono e outro de baixo teor de carbono (SAE 1005). Através deste desenvolvimento, barras com $12,7 \mathrm{~mm}$ de diâmetro foram submetidas ao processo de trefilação para se obter a bitola de 1,25 $\mathrm{mm}$ em dezesseis passes, onde foram determinadas as propriedades mecânicas por meio de ensaios de tração uniaxial, medidas de redução de área e dureza após cada passe de trefilação. Os aços estudados neste trabalho suportaram deformações verdadeiras da ordem de 4,6 em redução de área na trefilação e foi mostrado que o aço ultra-baixo carbono possui maior capacidade de deformação plástica que o aço baixo carbono. Com este trabalho foi possível determinar uma curva de previsão de resistência dos aços estudados em função de um plano de trefilação estabelecido, sendo esta utilizada para definição da aplicação final do produto.

Palavras-chave: Trefilação; Fio-máquina; Aço ultra-baixo carbono.

\section{DEVELOPMENT OF A ULTRA-LOW CARBON STEEL IN THE WIRE DRAWING PROCESS}

\section{Abstract}

The present work aims at comparing two grades of steel produced by basic oxygen furnace in the wire drawing process, was studied a ultra-low carbon steel and also a low carbon steel (SAE 1005). In this development, a bar $12.70 \mathrm{~mm}$ diameter was drawn to $1.25 \mathrm{~mm}$ diameter by using 16 dies. After each wire drawing reduction, the mechanical properties were evaluated by means of uniaxial tensile tests, reduction of area and hardness measurements. The steels studied in this work were submitted to 4.6 of true strain in reduction of area by drawing process and was showed that the ultra-low carbon steel has the formability higher than the low carbon steel. In this work was possible to determine a tensile strength forecast curve for both steels regarding a drawing plan. This forecast curve can be used to define the final application.

Keywords: Drawing process; Wire rod; Ultra low carbon steel.

1 M.Sc. em Engenharia Metalúrgica, Engenheiro de Desenvolvimento de Produtos e Assistência Técnica, CSN Aços Longos, Volta Redonda, RJ, Brasil.

2 D.Sc. Professor Associado, Programa de Pós-graduação em Engenharia Metalúrgica, Universidade Federal Fluminense, Volta Redonda, RJ, Brasil.

3 Engenheiro Metalúrgico, Gerente de Desenvolvimento de Produtos e Assistência Técnica, CSN Aços Longos, Volta Redonda, RJ, Brasil.

\footnotetext{
* Contribuição técnica ao 69 Congresso Anual da ABM - Internacional e ao 14ํㅡㄹ ENEMET - Encontro Nacional de Estudantes de Engenharia Metalúrgica, de Materiais e de Minas, 21 a 25 de julho de 2014, São Paulo, SP, Brasil.
} 


\section{INTRODUÇÃO}

A cada ano a siderurgia vem estudando alternativas no desenvolvimento de aços para atendimento a processos de beneficiamento cada vez mais severos, onde os aços são submetidos a maiores deformações e associados a elevadas taxas de deformações.

$\mathrm{Na}$ siderurgia de aços longos, os principais produtos laminados a quente são os tubos, perfis, trilhos, barras, vergalhões e fio máquina. O fio máquina, por sua vez, é o principal produto que é submetido a processos de beneficiamento antes de sua aplicação final, gerando produtos tais como arames trefilados, parafusos, porcas, pregos, rebites, eletrodos, peneiras, artefatos além de diversas outras aplicações.

Tendo em vista as alternativas de produção de fio máquina da Companhia Siderúrgica Nacional em Volta Redonda - RJ, é possível a produção de aços de ultra baixo carbono, que atualmente é largamente empregado na indústria automobilística no segmento de aços planos [1].

Este trabalho tem como objetivo conhecer e comparar em sucessivos passes de trefilação, o comportamento mecânico do aço ultra-baixo carbono em relação a um aço de baixo teor de carbono produzido também em aciaria LD. Uma vez que a passagem do material pela fieira provoca a redução de sua seção e, como o processo é realizado a frio, ocorre o encruamento com alteração das propriedades mecânicas do material [2].

\section{MATERIAIS E MÉTODOS}

\subsection{Materiais}

Para a realização deste trabalho, foram adotados um aço ultra-baixo carbono (UBC) e um aço baixo carbono (BC), ambos fornecidos pela Companhia Siderúrgica Nacional (CSN). A rota de fabricação para a produção dos aços contempla do recebimento de ferro gusa no convertedor a oxigênio (Aciaria LD), onde o oxigênio soprado pela lança reage com os elementos do gusa, oxidando-os e produzindo calor e no final do sopro, o aço não se apresenta na sua composição química objetivada, sendo necessárias adições de ferroligas e desoxidantes e subsequente processo de desgaseificação a vácuo para descarburação do aço e processo de lingotamento contínuo.

Os materiais foram disponibilizados em forma de placas provenientes de lingotamento contínuo, as quais foram cortadas em blocos de seção quadrada, conforme ilustração indicada na Figura 1. Os blocos foram laminados a quente em barras de seção circular com diâmetro de $12,70 \mathrm{~mm}$ para permitir o posterior processo de trefilação.

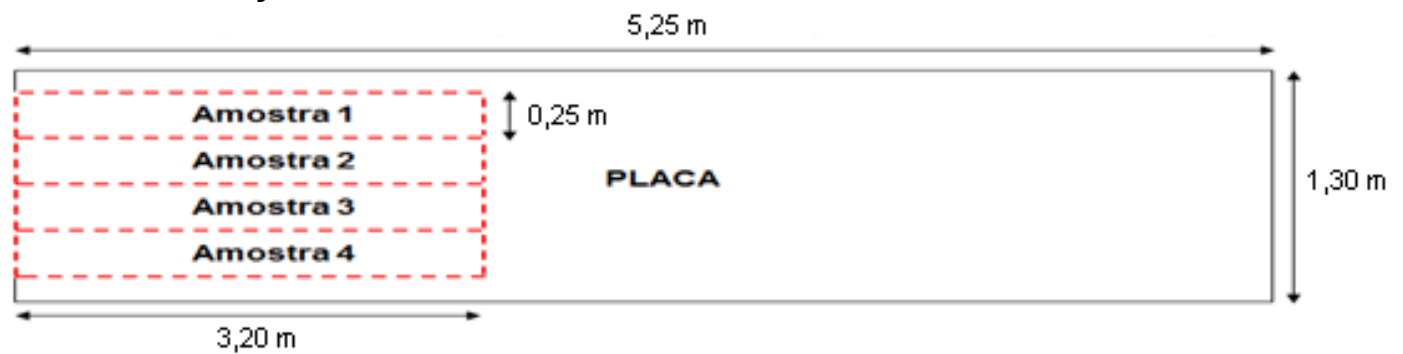

Figura 1. Amostras para laminação a quente.

\footnotetext{
* Contribuição técnica ao $69^{\circ}$ Congresso Anual da ABM - Internacional e ao 14ํㅡㄹ ENEMET - Encontro Nacional de Estudantes de Engenharia Metalúrgica, de Materiais e de Minas, 21 a 25 de julho de 2014, São Paulo, SP, Brasil.
} 


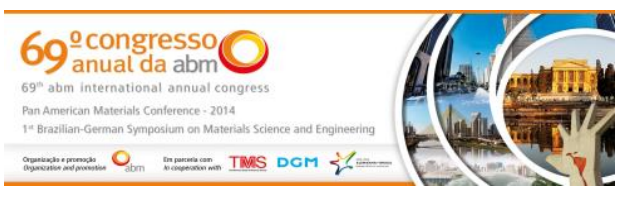

\subsection{Métodos}

Os procedimentos experimentais e metodologias foram divididos conforme a sequencia a seguir, na qual, foram realizados: (1) experimentos de laminação a quente para produção da bitola de $12,70 \mathrm{~mm}$, (2) experimentos de trefilação da bitola de $12,70 \mathrm{~mm}$ para a bitola de $1,25 \mathrm{~mm}$, (3) ensaios para caracterização experimental e (4) análises metalográficas.

\subsubsection{Laminação a quente}

Os blocos foram laminados pela empresa Ciafal, sendo produzidas barras de $6 \mathrm{~m}$ de comprimento com seção circular de $12,70 \mathrm{~mm}$ para permitir o posterior processo de trefilação. A figura 2 ilustra o processo de laminação utilizado para obtenção das barras, onde os tarugos foram aquecidos até a temperatura de $1.150^{\circ} \mathrm{C} \mathrm{e}$ submetidos a 16 passes de laminação, sendo 8 no desbaste, 5 no intermediário e 3 no acabador, com temperatura de saída do ultimo passe de aproximadamente $850^{\circ} \mathrm{C}$.

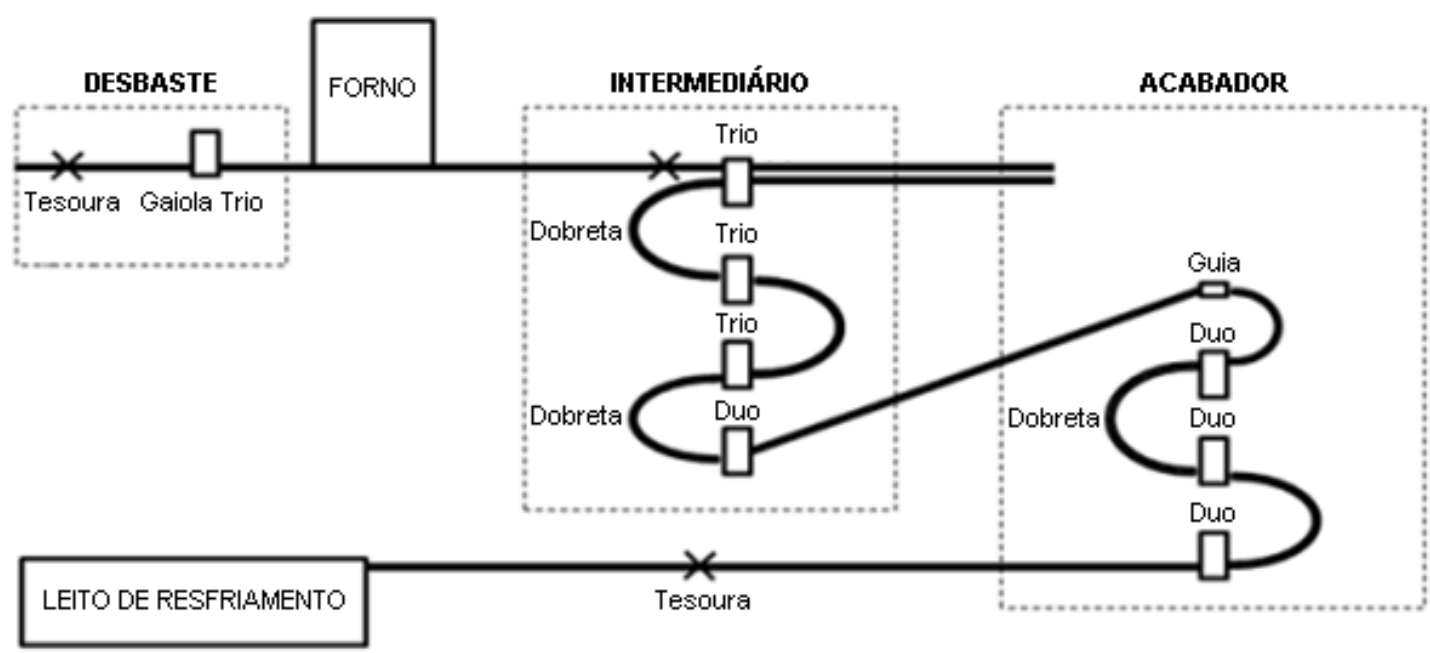

Figura 2. Laminação a quente.

\subsubsection{Trefilação}

O equipamento de trefilação utilizado para realização dos ensaios foi uma trefila do tipo monobloco vertical, contendo um passe de redução, onde o material de entrada pode se apresentar na forma de barra ou rolo, passado por uma caixa contendo sabão sólido (estearato de cálcio) que possui uma fieira de carboneto de tungstênio acoplada na saída da mesma, sendo na sequencia enrolado no bloco tracionador. Para obtenção da bitola trefilada de $1,25 \mathrm{~mm}$ foram realizados dezesseis passes de trefilação, com velocidade de processamento de aproximadamente $60 \mathrm{~m} / \mathrm{min}$, conforme indicado na Tabela 1.

Tabela 1. Plano de passes da primeira etapa de trefilação.

\begin{tabular}{|c|c|c|c|c|c|c|c|c|c|c|c|c|c|c|c|c|}
\hline Passe & $1^{\circ}$ & $2^{\circ}$ & $3^{\circ}$ & $4^{\circ}$ & $5^{\circ}$ & $6^{\circ}$ & $7^{\circ}$ & $8^{\circ}$ & $9^{\circ}$ & $10^{\circ}$ & $11^{\circ}$ & $12^{\circ}$ & $13^{\circ}$ & $14^{\circ}$ & $15^{\circ}$ & $16^{\circ}$ \\
\hline Bitola $(\mathrm{mm})$ & 11,05 & 9,65 & 7,95 & 7,08 & 6,25 & 5,50 & 4,50 & 3,73 & 3,12 & 2,65 & 2,27 & 1,97 & 1,73 & 1,53 & 1,38 & 1,25 \\
\hline Semi-ângulo $\left(^{\circ}\right)$ & 13 & 13 & 12 & 12 & 12 & 12 & 11 & 10 & 10 & 9 & 8 & 8 & 7 & 6 & 6 & 5 \\
\hline
\end{tabular}

Após cada passe de trefilação, retirou-se uma amostra com aproximadamente $1 \mathrm{~m}$ de comprimento para caracterização do material, conforme ilustrado na Figura 3,

\footnotetext{
* Contribuição técnica ao $69^{\circ}$ Congresso Anual da ABM - Internacional e ao 14ํㅡㄹ ENEMET - Encontro Nacional de Estudantes de Engenharia Metalúrgica, de Materiais e de Minas, 21 a 25 de julho de 2014, São Paulo, SP, Brasil.
} 
possibilitando a realização de até 3 ensaios de tração uniaxial, medições de dureza, corte e preparação de amostras para análises metalográficas.

A cada retirada de amostra, o material previamente trefilado foi novamente apontado e, em seguida, o ferramental da caixa de fieira foi substituído para realização do próximo passe.

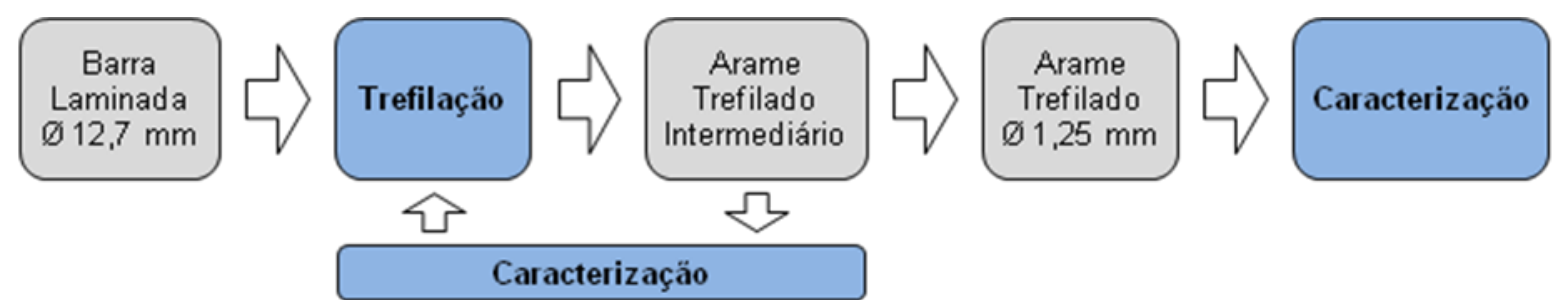

Figura 3. Trefilação.

\subsubsection{Caracterização experimental}

Foram realizados ensaios de tração uniaxial entre os passes de trefilação, considerando uma amostragem para cada passe de trefilação, com o objetivo de conhecer o comportamento mecânico dos materiais submetidos aos passes de trefilação. Para realização dos ensaios foi utilizada uma máquina universal de ensaios com capacidade de carga de $250 \mathrm{kN}$, do fabricante INSTRON, modelo $5585 \mathrm{H}$ com sistema de vídeo extensometria, onde o registro do deslocamento das marcações da base de medida é realizado por uma câmera, ou seja, sem contato com a amostra. A célula de carga utilizada possui capacidade de $30 \mathrm{kN}$ e precisão de $10 \mathrm{~N}$.

$\mathrm{Na}$ caracterização microestrutural foram utilizadas as mesmas amostras coletadas a cada passe, onde as superfícies polidas sofreram ataque químico com solução de Nital $3 \%$ durante $10 \mathrm{~s}$ e ataque de Klemms ( $1 \mathrm{~g}$ de metabisulfito de potássio e $50 \mathrm{ml}$ de tiossulfato de sódio saturado) durante cerca de 2 a 3 minutos, para os aços BC e UBC, respectivamente [3].

\section{RESULTADOS E DISCUSSÃO}

Após a realização da laminação a quente para obtenção das barras de 12,7 mm de diâmetro, foram realizados ensaios mecânicos de tração uniaxial, medidas de dureza, exame de inclusões e caracterização microestrutural. Estes resultados estão apresentados nas Tabelas 2 e 3. Observou-se um elevado nível de limpeza nos aços disponíveis para realização dos trabalhos de trefilação.

Tabela 2. Propriedades mecânicas dos aços laminados a quente.

\begin{tabular}{|c|c|c|c|c|}
\hline AÇO & $\begin{array}{c}\text { LR } \\
(\mathrm{MPa})\end{array}$ & $\begin{array}{c}\text { Redução de } \\
\text { Área (\%) }\end{array}$ & $\begin{array}{c}\text { Alongamento } \\
(\%)\end{array}$ & $\begin{array}{c}\text { Dureza } \\
(\mathrm{HRB})\end{array}$ \\
\hline BC & 328 & 82 & 38 & 63 \\
\hline UBC & 282 & 93 & 41 & 42 \\
\hline
\end{tabular}

Tabela 3. Propriedades mecânicas dos aços laminados a quente.

\begin{tabular}{|c|c|c|c|c|c|c|}
\hline \multirow{2}{*}{ AÇO } & \multirow{2}{*}{ Sulfetos } & \multirow{2}{*}{ Aluminatos } & \multirow{2}{*}{ Silicatos } & \multicolumn{2}{|c|}{ Óxidos } & \multirow{2}{*}{$\begin{array}{c}\text { Tamanho de Grão } \\
(\mu \mathrm{m})\end{array}$} \\
\hline & & & & Fino & Grosso & \\
\hline $\mathrm{BC}$ & - & - & - & 1 & - & 15 \\
\hline UBC & - & - & - & 1 & - & 19 \\
\hline
\end{tabular}

\footnotetext{
* Contribuição técnica ao 69 Congresso Anual da ABM - Internacional e ao 14ํㅡㄹ ENEMET - Encontro Nacional de Estudantes de Engenharia Metalúrgica, de Materiais e de Minas, 21 a 25 de julho de 2014, São Paulo, SP, Brasil.
} 
Através de ensaios de tração uniaxial realizados após cada passe de trefilação, foi possível verificar a evolução das propriedades mecânicas dos aços avaliados. As Figuras 4 e 5 apresentam exemplos de gráficos de força versus deslocamento do aço UBC e as Figuras 6 e 7 para o aço BC, onde se percebe o aumento da resistência mecânica a medida que os materiais são reduzidos em sua seção transversal e maior capacidade de deformação plástica do aço UBC em relação ao $\mathrm{BC}$, indicado pelo maior alongamento total registrado no ensaio.

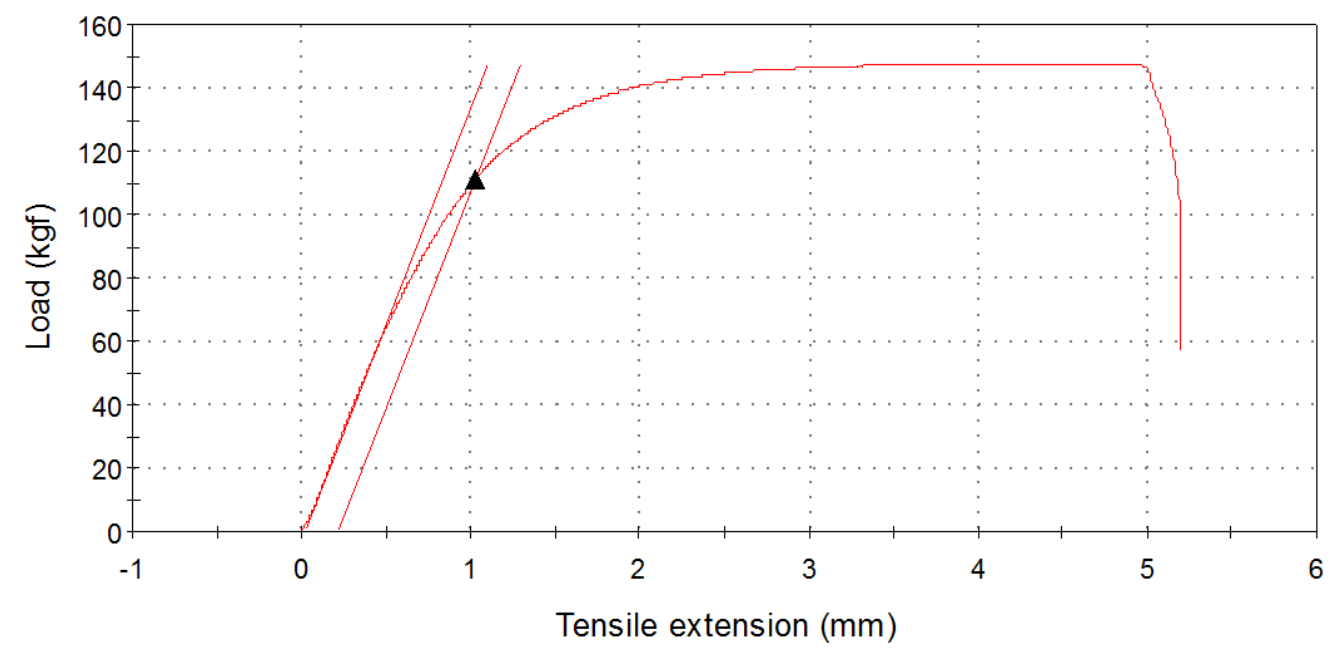

Figura 4. Gráfico Força (kgf) x Deslocamento $(\mathrm{mm})$ - Bitola de $1,38 \mathrm{~mm}$ aço UBC

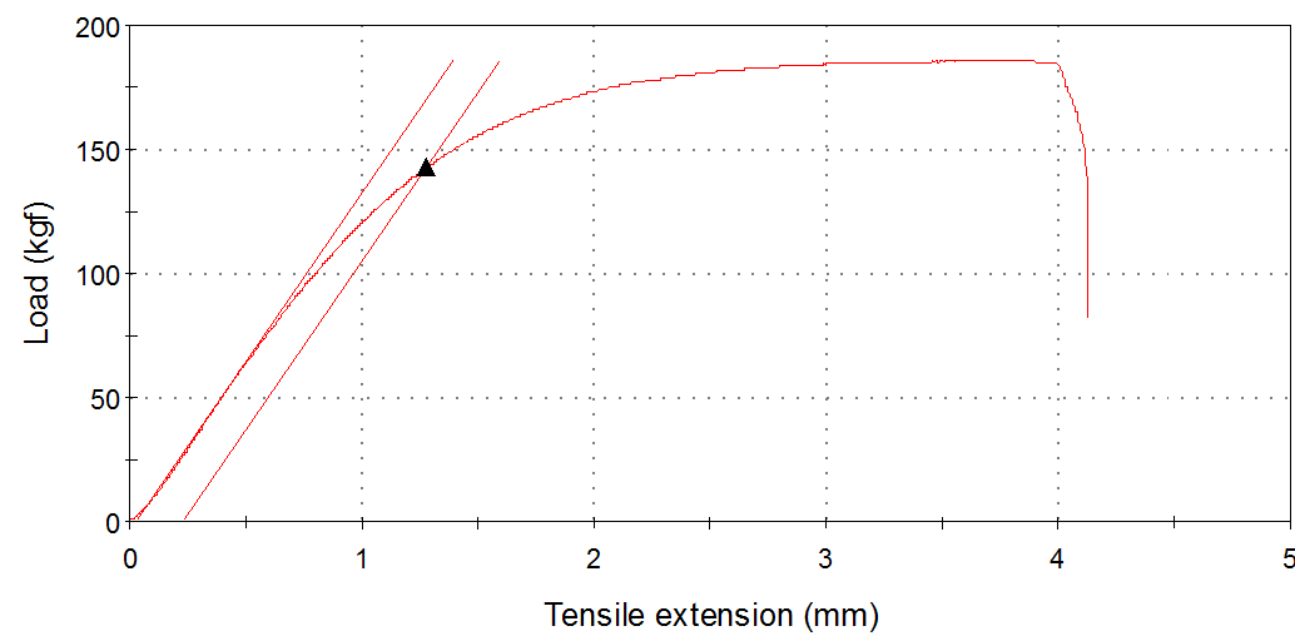

Figura 5. Gráfico Força (kgf) x Deslocamento $(\mathrm{mm})$ - Bitola de 1,38 $\mathrm{mm}$ aço BC

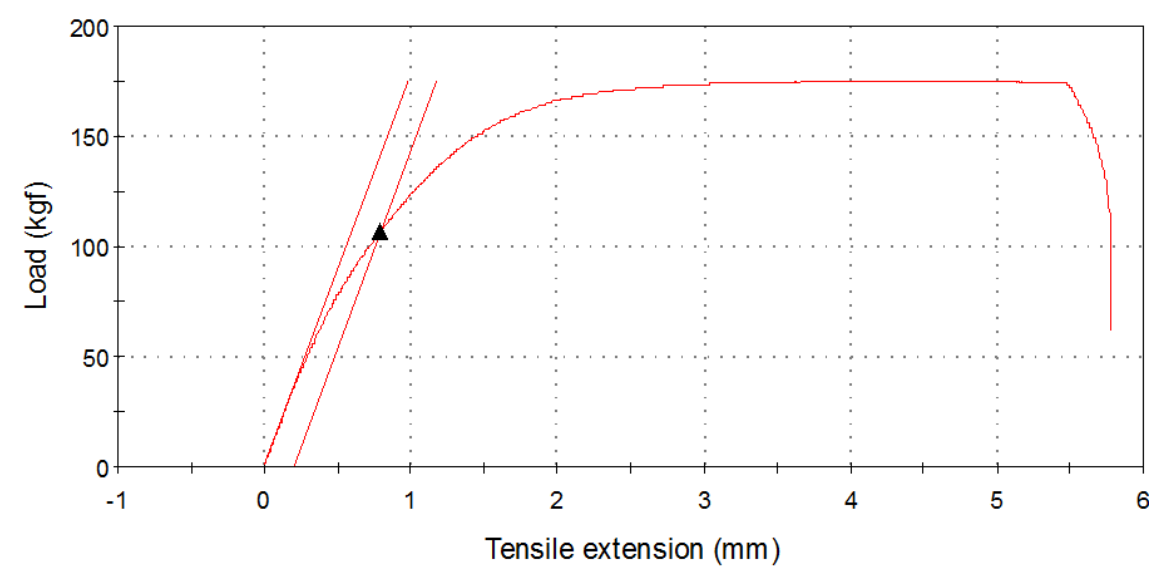

Figura 6. Gráfico Força (kgf) x Deslocamento $(\mathrm{mm})$ - Bitola de 1,53 $\mathrm{mm}$ aço UBC

* Contribuição técnica ao 69 Congresso Anual da ABM - Internacional e ao 14ํㅡㄹ ENEMET - Encontro Nacional de Estudantes de Engenharia Metalúrgica, de Materiais e de Minas, 21 a 25 de julho de 2014, São Paulo, SP, Brasil. 

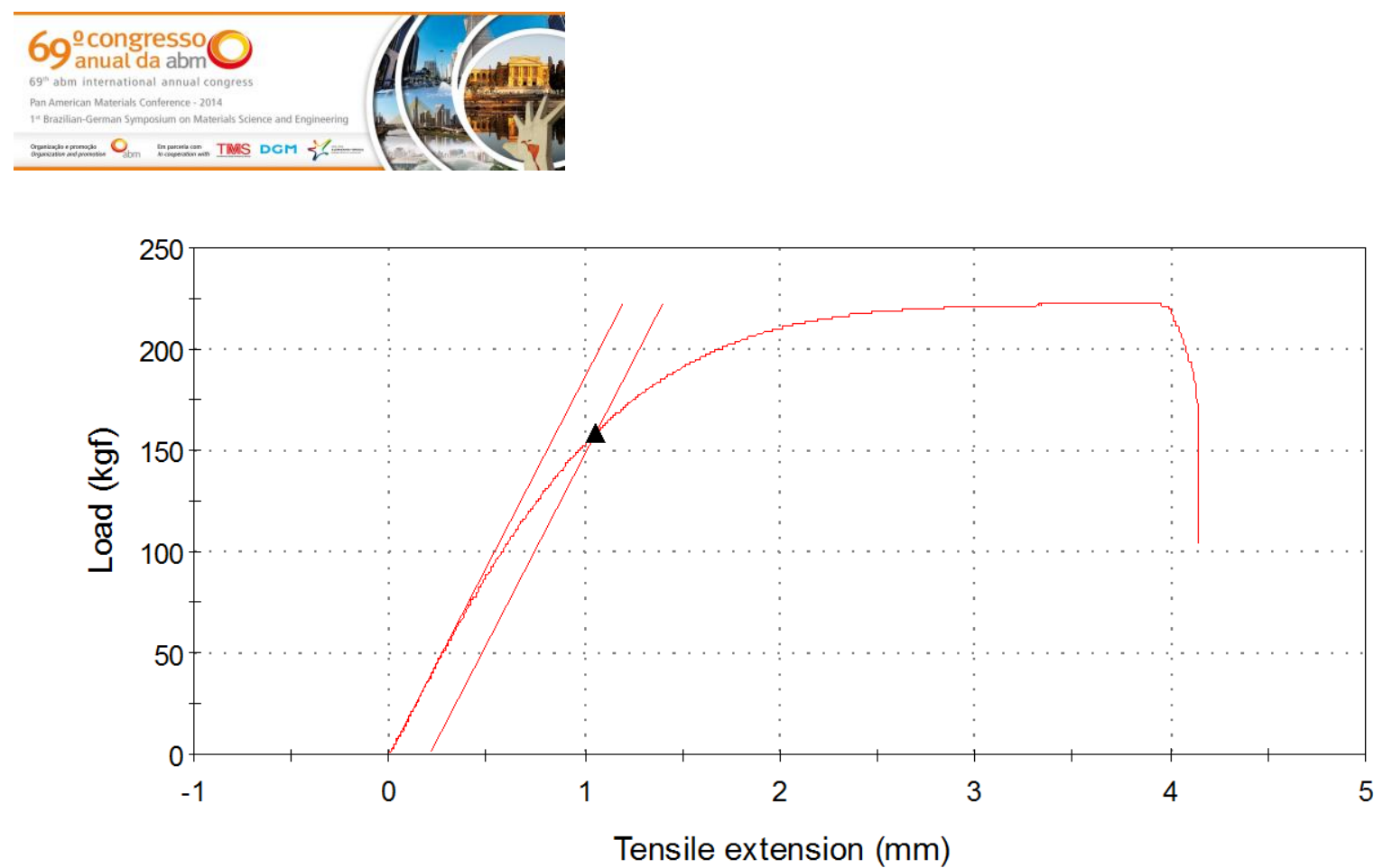

Figura 7. Gráfico Força $(\mathrm{kgf}) \times$ Deslocamento $(\mathrm{mm})$ - Bitola de $1,53 \mathrm{~mm}$ aço $\mathrm{BC}$

Considerando os valores de limite de resistência a tração, obtidos a cada passe de trefilação e relacionando o respectivo valor de redução de área devido ao passe de trefilação, a Figura 8 mostra essa relação para cada passe de trefilação realizado subsequentemente. A taxa de endurecimento para um arame trefilado é definida como o aumento no limite de resistência a tração dado pela quantidade de redução de área após o trabalho a frio [4].

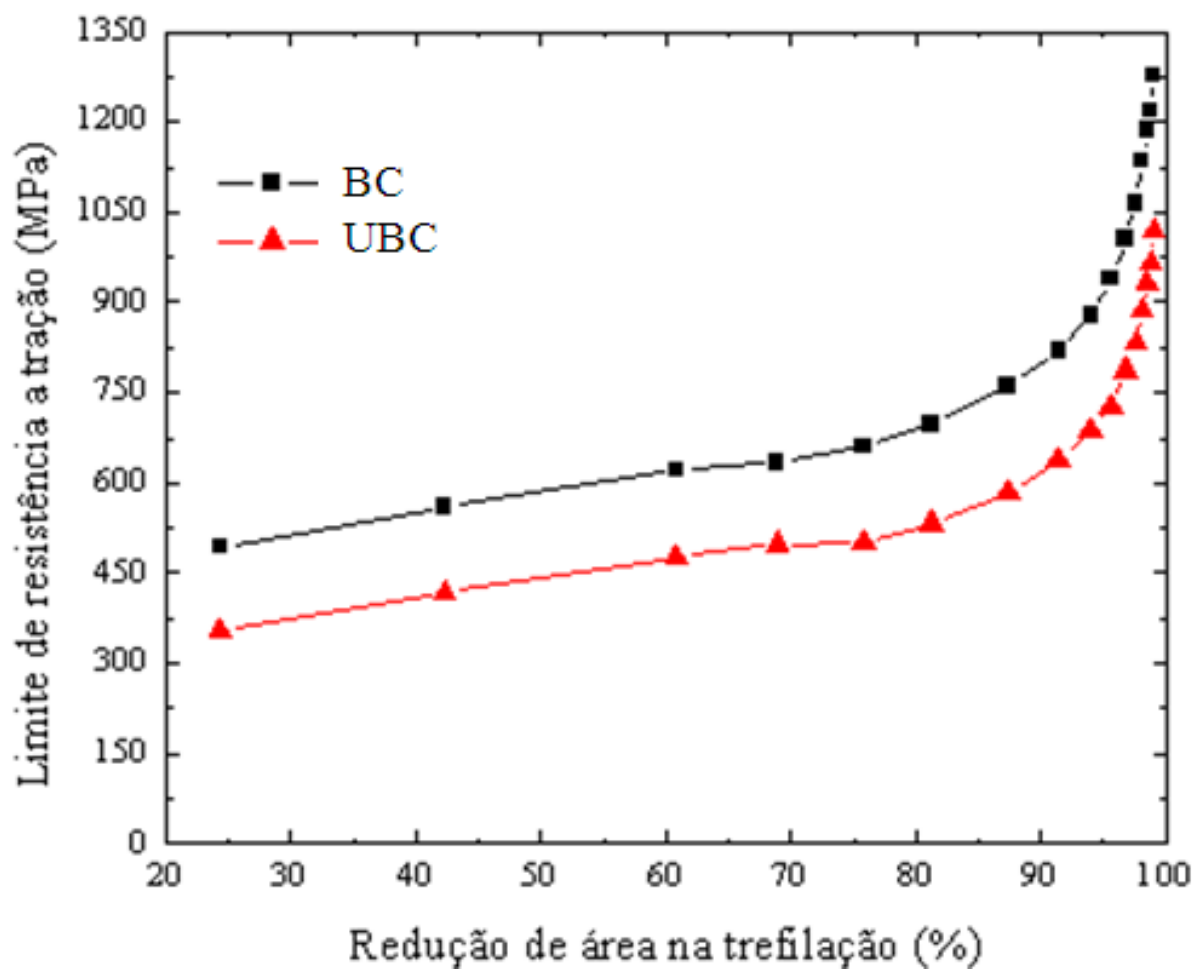

Figura 8. Evolução da resistência a tração em função da redução de área em trefilação.

Considerando os valores de resistência a tração obtidos em cada passe de trefilação e seu respectivo valor de redução de área registrado no ensaio de tração a Figura 9 mostra essa relação a cada passe de trefilação realizado subsequentemente.

* Contribuição técnica ao 69ำ Congresso Anual da ABM - Internacional e ao 14ํㅡㄹ ENEMET - Encontro Nacional de Estudantes de Engenharia Metalúrgica, de Materiais e de Minas, 21 a 25 de julho de 2014, São Paulo, SP, Brasil. 

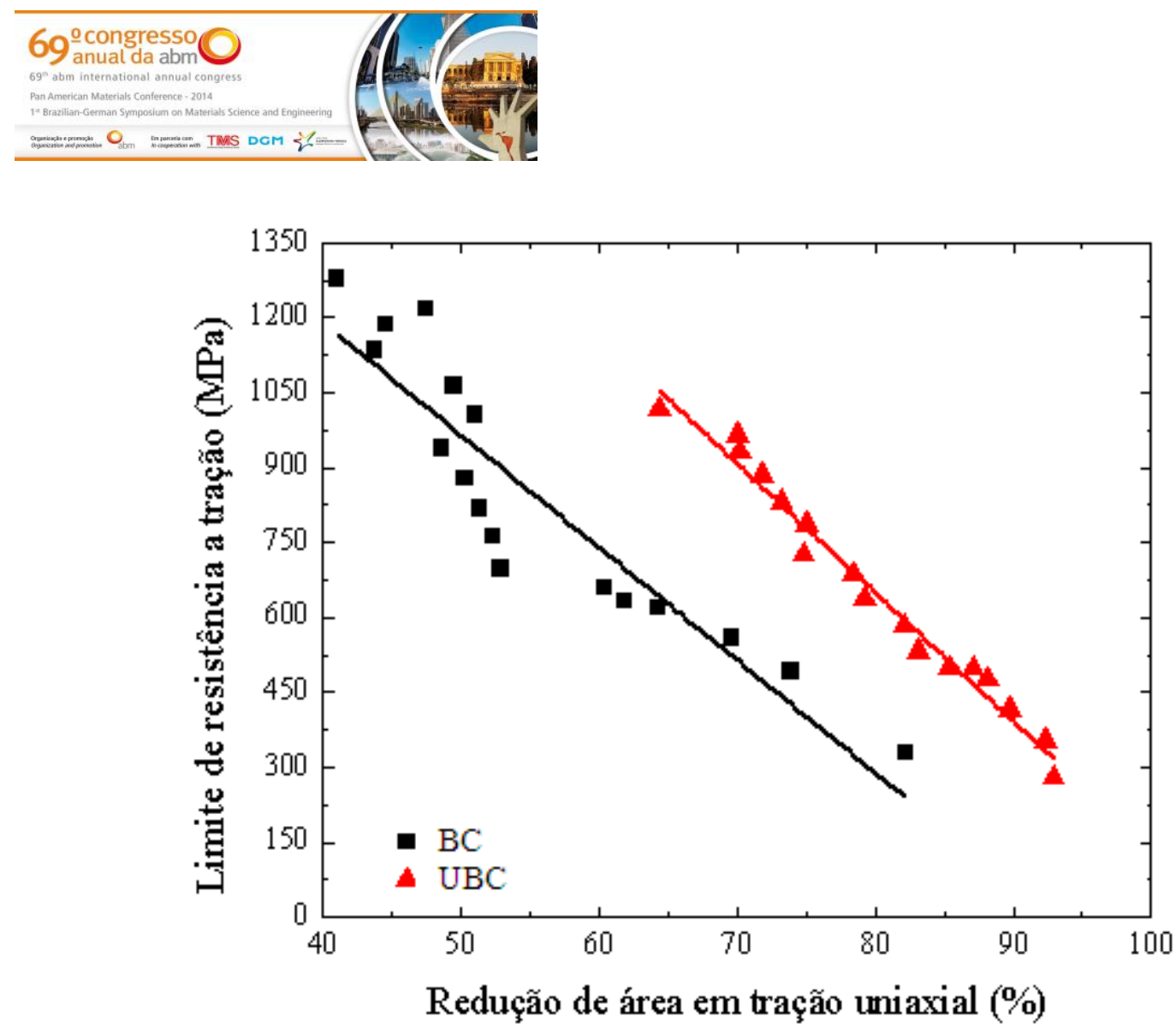

Figura 9. Evolução da resistência a tração em função da redução de área em tração uniaxial.

A Figura 10 mostra a região onde ocorreu estricção no corpo de prova de ensaio de tração uniaxial, sendo este o local de medição de redução de área.

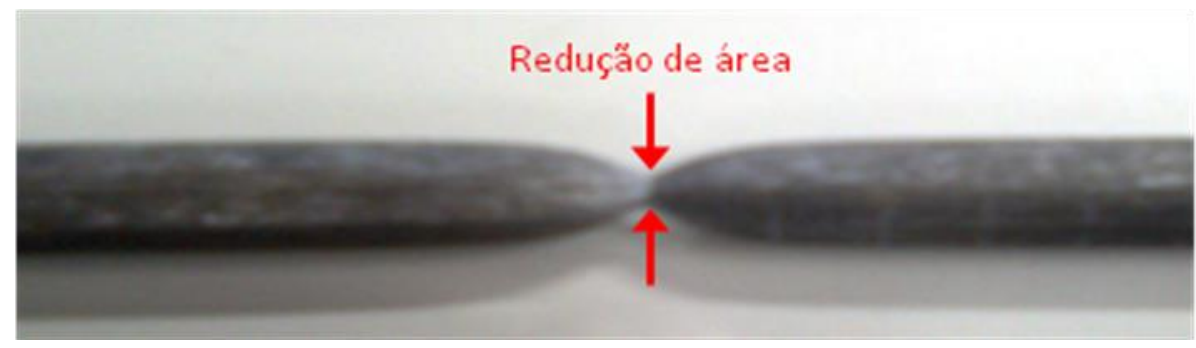

Figura 10. Redução de área - Local de Medição.

As Figuras de 11 a 14 apresentam as micrografias na bitola de $1,25 \mathrm{~mm}$ do aço UBC e BC que sofreram dezesseis passes, apresentando deformação verdadeira de 4,6 (99\% de redução de área). Nestas figuras foi possível observar a acentuada deformação ocorrida nos grãos, de forma a se tornarem mais alongados a medida que os passes de trefilação foram realizados.

\footnotetext{
* Contribuição técnica ao 69ำ Congresso Anual da ABM - Internacional e ao 14ํㅡㄹ ENEMET - Encontro Nacional de Estudantes de Engenharia Metalúrgica, de Materiais e de Minas, 21 a 25 de julho de 2014, São Paulo, SP, Brasil.
} 

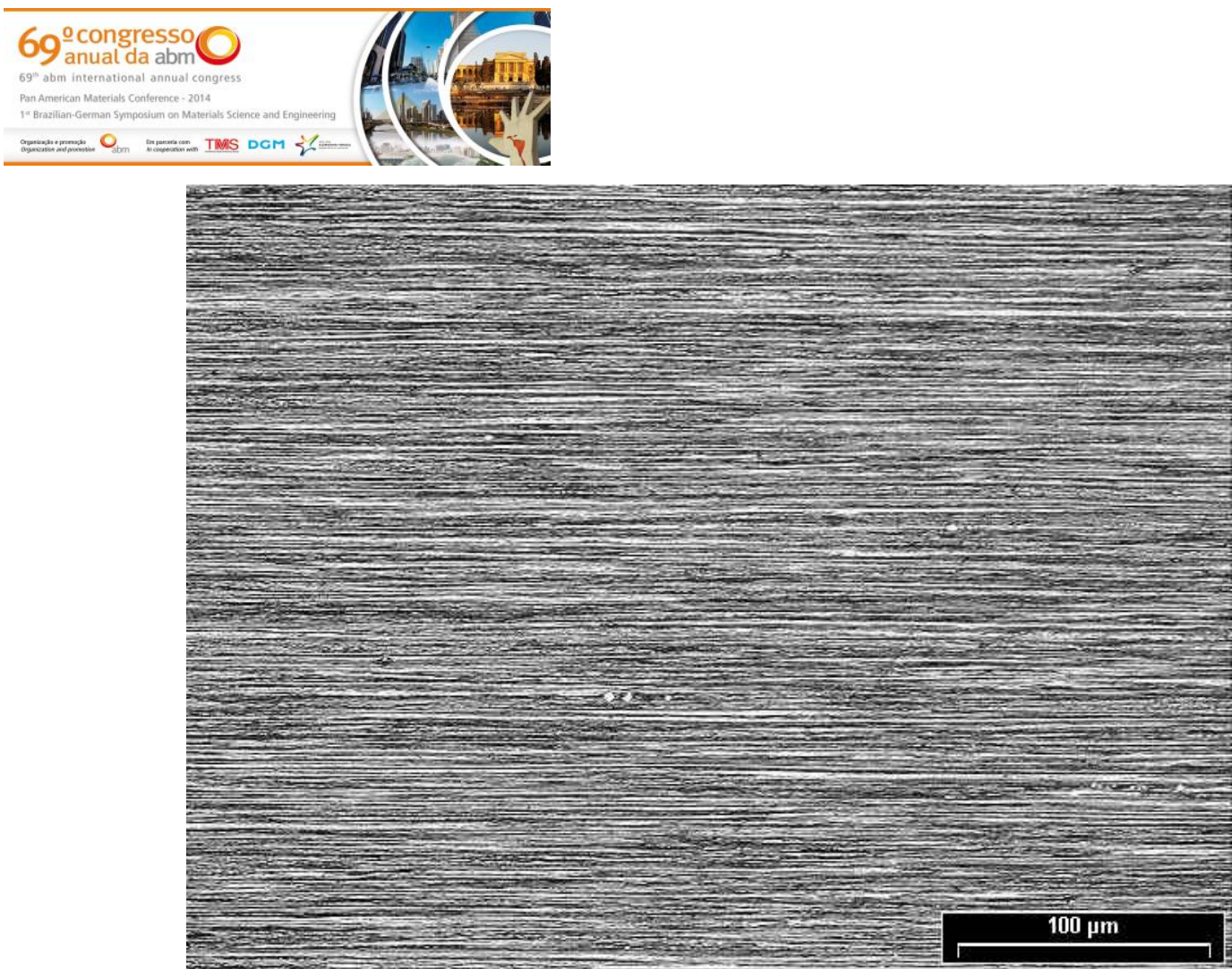

Figura 11. Micrografia aço UBC com 200X de aumento - Bitola 1,25 mm.

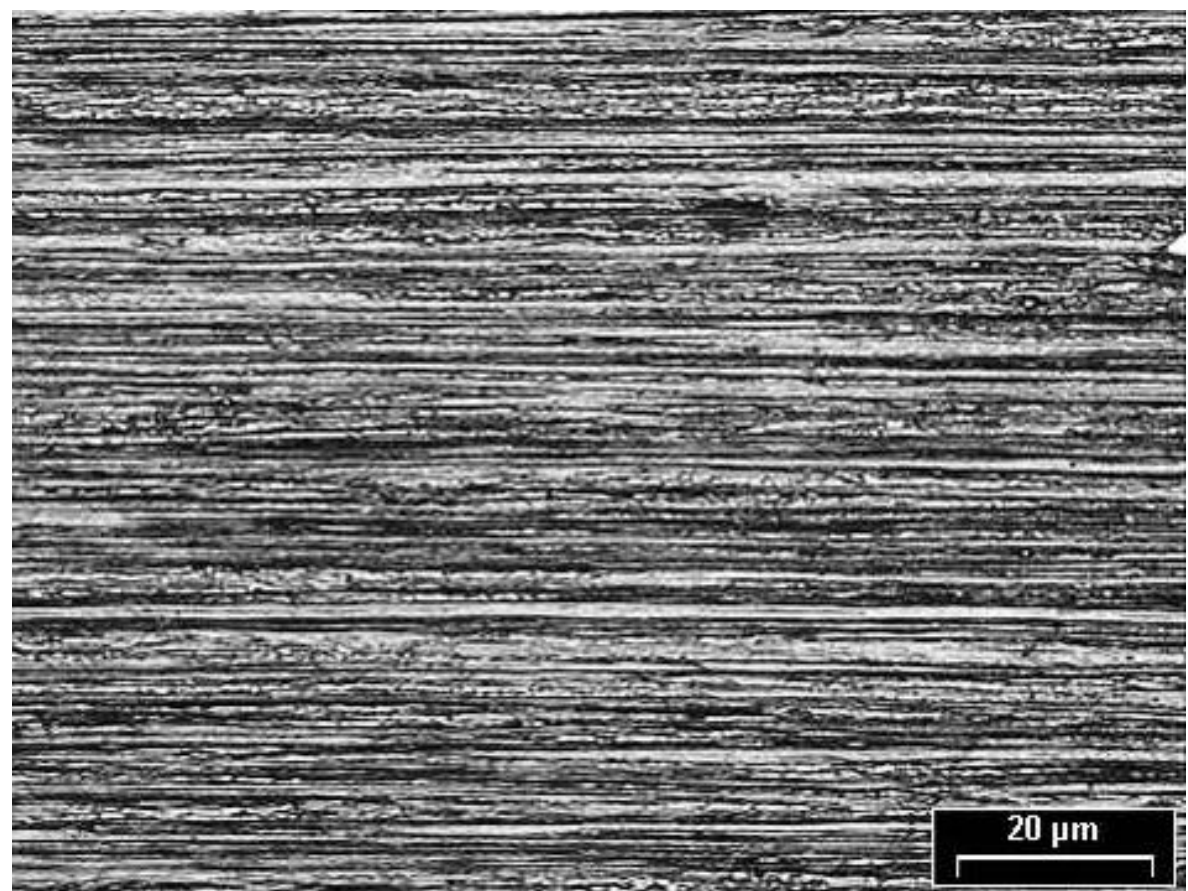

Figura 12. Micrografia aço UBC com $500 X$ de aumento - Bitola 1,25 mm

* Contribuição técnica ao 69 Congresso Anual da ABM - Internacional e ao 14ํㅡㄹ ENEMET - Encontro Nacional de Estudantes de Engenharia Metalúrgica, de Materiais e de Minas, 21 a 25 de julho de 2014, São Paulo, SP, Brasil. 

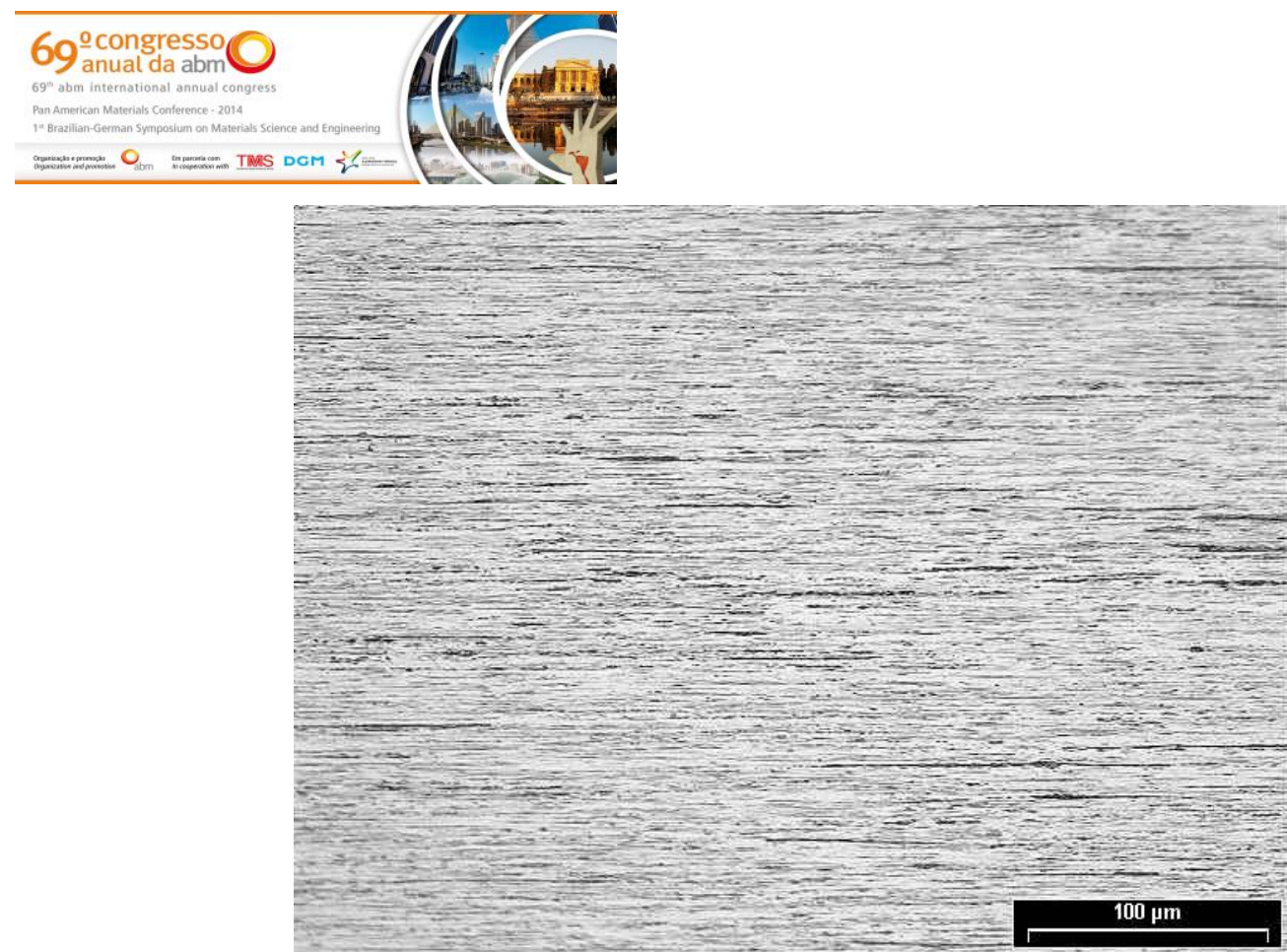

Figura 13. Micrografia aço BC com $200 X$ de aumento - Bitola $1,25 \mathrm{~mm}$.

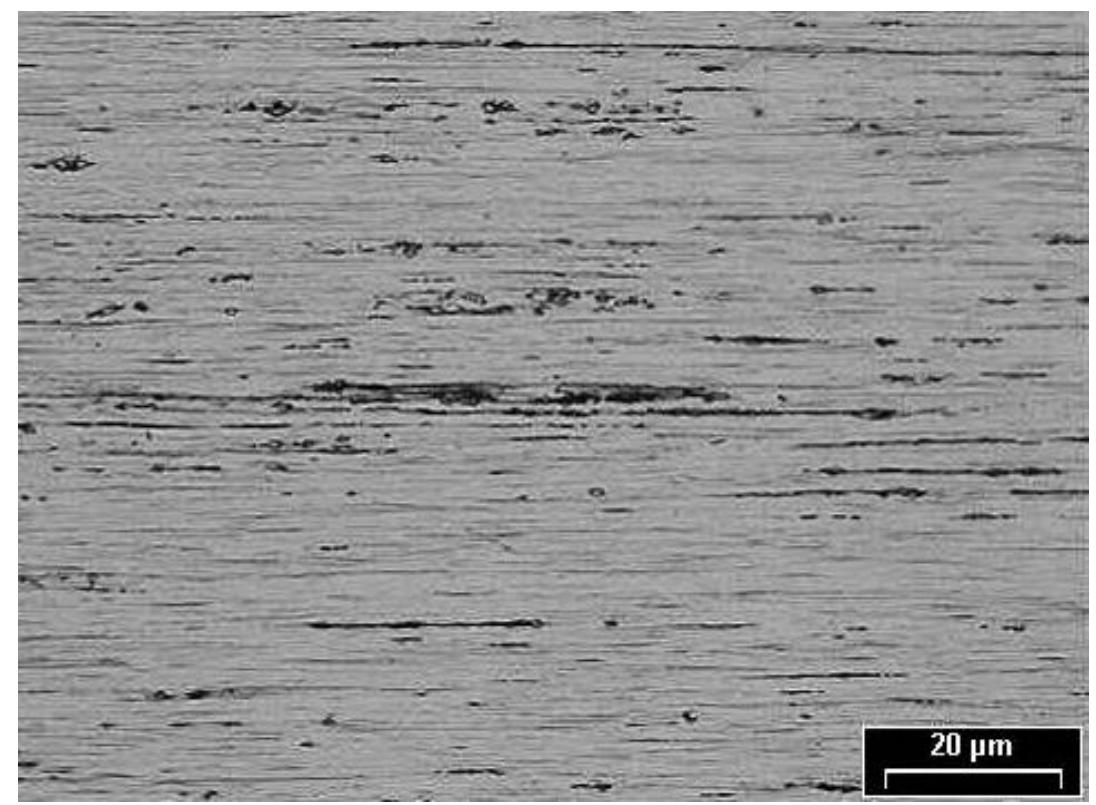

Figura 14. Micrografia aço $B C$ com $500 X$ de aumento - Bitola $1,25 \mathrm{~mm}$.

\section{CONCLUSÕES}

Com base nos experimentos de trefilação e nos ensaios de tração uniaxial, medidas de dureza e análises metalográficas realizadas em amostras de aços UBC e BC, foi possível estabelecer as seguintes conclusões:

1) ambos os aços atingiram deformação verdadeira da ordem de 4,6 sem apresentarem defeitos ou falta de capacidade de trefilação;

2) para atingir uma mesma resistência, o aço UBC deve sofrer mais encruamento;

3) a relação entre a redução de área observada no ensaio de tração e a resistência do material possui uma relação linear;

4) o aço UBC apresentou maior capacidade de deformação a frio em comparação ao aço BC;

5) foi possível estabelecer um modelo de previsão de resistência do arame trefilado em função do plano de trefilação;

\footnotetext{
* Contribuição técnica ao 69 Congresso Anual da ABM - Internacional e ao 14ํㅡㄹ ENEMET - Encontro Nacional de Estudantes de Engenharia Metalúrgica, de Materiais e de Minas, 21 a 25 de julho de 2014, São Paulo, SP, Brasil.
} 
6) o aço UBC pode ser aplicado em trefilação de arames finos e possivelmente eliminar etapas de recozimento intermediário em aplicações onde se utilizam aços com resistência superior.

\section{Agradecimentos}

Os autores gostariam de agradecer a empresa Messa \& Messa pelo apoio na realização dos ensaios de trefilação e à Companhia Siderúrgica Nacional pelos recursos disponibilizados.

\section{REFERÊNCIAS}

1 Meira RR. Efeito da Variação das Condições de Encharque nas Propriedades Mecânicas do Material IF Processado no Recozimento Contínuo da Usiminas; Dissertação de mestrado, cap. 1, p. 13 - Belo Horizonte, 2006.

2 Bresciani Filho E, Iris Bento da Silva, Gilmar Ferreira Batalha e Sérgio Tonini Button Conformação Plástica dos Metais, 6⿳a Edição - Campinas 2011.

3 Carvalho CRG. - Estudo da cinética de recristalização num aço IF estabilizado ao titânio com adição de silício; Dissertação de mestrado, cap. 3, p.63-64 - São Paulo, 2004.

4 Yalamanchili B, Power PM, Lanham D. A technical review of industrial practices for decreasing the strain hardening rate of low carbon steel wire - Wire Journal International, 2005; 38(7).

* Contribuição técnica ao $69^{\circ}$ Congresso Anual da ABM - Internacional e ao 14ํㅡㄹ ENEMET - Encontro Nacional de Estudantes de Engenharia Metalúrgica, de Materiais e de Minas, 21 a 25 de julho de 2014, São Paulo, SP, Brasil. 